\title{
Burnout, vigour, big five personality traits and social support in a sample of police officers
}

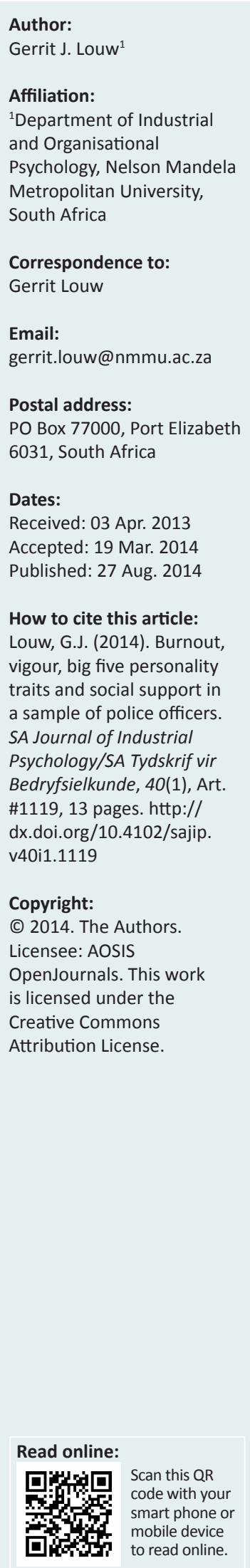

Orientation: Burnout occurs as a result of prolonged job stress, which is a phenomenon prevalent amongst police officers in South Africa. Whilst some suffer from burnout, others elude the pathological effects of burnout and execute their duties vigorously under the same circumstances.

Research purpose: The purpose of the study was to obtain an understanding of a police officer's need to reduce the effects of prolonged stressors and to utilise personal and social sources to mitigate the effects of negative stressors.

Motivation for the study: Burnout causes negative health consequences for police officers. Those who are affected reflect withdrawal behaviour through operational disruption or lower productivity in the work context.

Research design, approach and method: The research has a non-experimental design in the quantitative tradition with a cross-sectional data-collection method. The availability sample $(N=505)$ included participants from different demographic backgrounds. A survey was used to measure all constructs at a single point in time.

Main findings: Neuroticism and a lack of family support predicted burnout whilst conscientiousness and emotional stability predicted vigour. This was followed by significant other, which predicted physical strength, friend support which predicted emotional energy and family support which predicted cognitive liveliness.

Practical/managerial implications: The study provides markers for selection purposes and calls on police management to be aware of the value of social support in the prevention of burnout whilst encouraging supervisor support in operational designs.

Contribution/value-add: The study adds to the body of knowledge on the role of personality and social support in burnout and vigour in police officers.

\section{Introduction}

\section{Background to the study}

Police work has been ranked amongst the most stressful occupations worldwide (Anshel, 2000; Newell, 2002; Sims, 2002) and generates high levels of physical and mental problems amongst employees, leading to high levels of sickness, burnout and premature retirement (Adams \& Buck, 2010; Anshel, 2000). Since the 1990s, disability claims from insurance on the grounds of psychological impairment have been increasing steadily. More and more working-class people have become disabled due to work stress (Coetzer \& Emsley, 1996; Hugo, Emsley, Theron, De Villiers \& Hemp, 2001) with the police, military and teaching professions having the highest prevalence of disability claims in South Africa (Mokoka, Rataemane \& Dos Santos, 2012).

Police officers provide protection services to the public whilst simultaneously being exposed to various organisational and social stressors over which they have little or no control (Larsen \& Buss, 2005). Negatively perceived stress (distress) without sufficient coping mechanisms causes burnout (Dorz, Novara, Sica \& Sanavio, 2005). Burnout is a consequence of decreasing energy resources, and it is therefore reasonable to assume that burnout will predict a reduction in an individual's perceived health status (Shirom, 2009). The outcome of this may be that highly committed and loyal officers become psychologically burned out. Paradoxically some of their colleagues may function energetically and proactively whilst experiencing a positive emotional state (vigour) during the execution of their duties under the same challenging circumstances (Cooper \& Bagloni, 1988; Nakao, 2010). Vigour therefore stands in sharp contrast to its counterpart, burnout (Shirom, 2004; 2007). The question that arises is why some officers lack energy whilst others are energetic in the fulfilment of their jobs under the same conditions. 


\section{Trends from the literature}

When perusing the literature, one can observe a pattern of gradual increase in burnout literature. Two major trends seem to have emerged since burnout became a point of interest in research. One trend refers to a continuous search for improved ways to measure burnout (Demerouti, Bakker, Nachreiner \& Schaufeli, 2001; Kristensen, Borritz, Villadsen \& Christensen, 2005; Schaufeli, Leiter, Maslach \& Jackson, 1996; Shirom, 2004; Sonnentag, 2005). The second major trend in burnout research is the increased use of longitudinal designs (Bakker, Schaufeli, Sixma, Bosveld \& Van Dierendonck, 2000; Kim, Ji \& Kao, 2011; Okabayashi et al. 2008; Sonnentag, 2005).

Burnout was initially studied from a pathogenic point of view (Guse, 2010; Maslach, Schaufeli \& Leiter, 2001). More recent research attempts to study the phenomenon from a salutogenic point of departure (Guse, 2010; Hakanen, Schaufeli \& Ahola, 2008; Söderfeldt, Söderfeldt, Ohlson, Theorell \& Jones, 2000). Several models emerged from this change in stress and stress-relevant research. These models are however not without limitations when it comes to a holistic view on burnout research. The Maslach (1998) and Pines models (Pines, Aronson \& Kafry, 1981) are the two most important models developed for burnout research, leading to research being done mostly from the perspective of either the Maslach (1998) or Pines burnout model (Pines et al., 1981). Although these models were used within a work context, they tended to either carry over symptoms (e.g. cynicism, disengagement) or define burnout as a syndrome of symptoms (e.g. helplessness, hopelessness, entrapment, decreased enthusiasm and irritability) that are more meaningful for human-service professionals. In contrast, the Shirom-Melamed burnout model is theoretically constructed to reflect the decrease in energetic resources at work regardless of the work context (Shirom \& Ezrachi, 2003; Shirom \& Melamed, 2006).

Mainstream organisational-stress models, such as the jobdemands resources model and the comprehensive burnout and engagement model (COBE), suggest that a stress outcome such as burnout is mainly predicted by job demands and a lack of resources. In the same vein, engagement is exclusively predicted by the availability of resources (Bakker, Demerouti \& Verbeke, 2004; Rothmann \& Jorgensen, 2007; Shaufeli \& Bakker, 2004). In contrast to the above models, Shirom (2003) proposed an alternative to burnout research with Hobfoll's conservation of resources (COR) theory as the philosophical foundation (Hobfoll \& Shirom, 2000). According to Shirom (2003), burnout is an affective state that is likely to exist when an individual experiences resource loss over a period of time. In contrast, those who are not affected by any form of resource loss continue to experience a positive affective state called vigour (Shirom, 2004; 2007). Vigour is in essence the antithesis of burnout. The bivariate relationship between burnout and vigour as suggested by Shirom (2003, 2004) actually embraces both a pathogenic and salutogenic way of explaining affective experiences at work (Antonovsky, 1987; Van Wijk \& Waters, 2008).
When considering the above trends and when exploring research on coping with the burnout syndrome, several gaps become evident in the research. For example, researchers investigating the mediating or moderating relationship of personality and social support as independent variables and burnout as a dependent variable do not use the same approach, samples or instruments to reach their conclusions (Bakker, Van der Zee, Lewig \& Dollard, 2006; Mede, 2009; Pienaar, Rothmann \& Van de Vijver, 2007; Salami, 2011). In addition, the combined effect of personality and social support on the dimensions of burnout and vigour in police samples is not known. Furthermore, a police research sample has not previously been used in burnout research, specifically with burnout and vigour as bivariate outcomes as defined by Shirom (2004; 2007). The relationship of these two constructs to personality and social support has also not been established in police samples previously. Much still needs to be learned regarding the relationship between these two constructs, social support and personality (Hobfoll \& Shirom, 2000).

The main objective of the study is therefore to investigate the combined effect of dimensions of the big five personality traits and perceived social support on burnout and vigour as two antipodes of an affective experience at work. Two specific research objectives emanate from the above research gaps. The first is to determine the combined effect of the five factor personality dimensions and the perceived social support dimensions on the dimensions of burnout as defined in this article. The second specific objective would be to determine the combined effect of the five factor personality dimensions and perceived social support on the dimensions of vigour as defined in this article.

\section{Literature review}

The individual's intra-psychological functioning plays a decisive role in the maintenance of individual psychological health. This functioning is triggered by environmental threats, challenges or life crises and results in individual burnout, depending on the individual's ability to exercise control over the situation. Under the same circumstances, some individuals are not affected, thus reflecting a different phenomenon (Louw \& Viviers, 2010; Shirom, 2007). This phenomenon, which is the antithesis of burnout, is referred to as vigour (see Shirom, 2004).

Police officers do not operate in isolation, and aspects such as stable personality traits (Kaplan, 1996; Louw \& Viviers, 2010) and social interaction in work and social context (Akert, Aronson \& Wilson, 2007; Cassel, 1976) seem to be significant in the stress-mitigating process. Lord (2005) found that social support can play different roles in the stress-mitigation process. For example, people who are suffering from burnout may withdraw from social contact as a result of the depersonalisation effect whilst other individuals may seek social interaction in order to reduce stress. It can therefore be assumed that, if stress is not prolonged, individuals would prefer social contact. A police officer therefore needs support 
resources in the process of handling stress in order to prevent burnout. The aforementioned research objective warrants a discussion of the critical variables under investigation in the empirical study of this research, commencing with burnout.

Burnout was first recognised as a psychological problem amongst healthcare and social-service professionals but soon extended to other occupations such as clerical, computer technology, military (Maslach et al. 2001), education (Faber, 2000), police (Adams \& Buck, 2010) and pharmacy (Storm \& Rothmann, 2003). What is also evident is that burnout as a social problem was identified by both practitioners and social commentators long before it became a focus of systematic study by health researchers (Maslach et al. 2001).

Burnout: as a construct relates to a loss in energetic resources such as physical, emotional and cognitive energy. In essence, burnout represents a combination of physical fatigue, emotional exhaustion and cognitive weariness. According to the conservation of resources (COR) theory (Hobfoll, 1998), stress at work occurs when individuals are either threatened with resource loss, do lose resources or fail to regain resources. One of the propositions of COR theory is that stress does not occur as a single event but rather represents an unfolding process wherein those who lack a strong resource pool are more likely to experience cycles of resource loss. Burnout is an affective state which is likely to exist when an individual experiences resource loss at work over a period of time (Hobfoll \& Freedy, 1993). As mentioned, vigour is the antithesis of burnout and is discussed in the next section. Whereas burnout is a pathogenic outcome of the stress and coping process, vigour represents an outcome that is explained in terms of positive psychology (Louw \& Viviers, 2010).

Vigour: refers to an individual's belief that he or she possesses physical strength, emotional energy and cognitive liveliness, which form a set of interrelated affective experiences (Shirom, 2007). Vigour may be described as the 'affective dimension of the energy reservoirs that employees possess' that could be used when dealing with challenges from the environment (Shirom, 2007, p. 86). Feeling vigorous is not only a positive experience, per se, but a phenomenon in everyday life, in work and in the family context. Vigour enables an individual to approach his or her tasks with more energy (Sonnentag \& Niessen, 2008). As vigour is one aspect of positive affect (Ryan \& Frederick, 1997; Sheldon, Ryan \& Reis, 1996), it may also stimulate creative, proactive and other forms of extrarole behaviour at work (e.g. taking initiative with specific tasks). Shirom (2007) argues that vigour and burnout are obliquely related and do not represent the extreme poles of the same continuum, perhaps with the exception of situations characterised by very high levels of stress (see also Reich \& Zautra, 2002). Vigour represents an affective state that individuals attribute to their job and workplace. Like burnout, vigour is also formulated on the COR theory as explained earlier in this text. Vigour reflects the mirror image of burnout and presents a combination of physical strength, emotional energy and cognitive liveliness (Shirom,
2004; 2007; 2011). The third variable under investigation is discussed in the next section.

Perceived social support: is defined by Zimet, Dahlem, Zimet and Farley (1988) as an individual's perception of how resources can act as a buffer between stressful events and symptoms. According to Zimet et al. (1988), perceived social support consists of three dimensions, namely family, friends and significant other. Whereas family and friends are self-explanatory, a significant other could be a supervisor, peer, co-worker or any other person not explicitly defined, but someone with whom the individual has contact on a daily basis. Support resources also refer to social support by peers or supervisors (Mede, 2009) or support outside of the organisation from friends and family (Galek, Flannelly, Greene \& Kudler, 2011). Like perceived social support, personality forms the fourth and last construct to be discussed in the next section.

Personality: is an individual's unique pattern of thoughts, feelings and behaviour that persist over time and across situations (Morris \& Maisto, 2012). Researchers (Costa \& McCrae, 2000; Goldberg, 1990) are of the opinion that the Five Factor model of personality is regarded as the most comprehensive taxonomy of personality in the work context. These authors view personality as a system defined by personality traits and dynamic processes which affects the way in which an individual functions socially as well as in a work context (Barrick \& Mount, 1991; Gatewood, Field \& Barrick, 2011). The five broad dimensions (subscales) identified by Goldberg (1990; 1992) are: introversion versus extraversion; antagonism versus agreeableness; lack of direction versus conscientiousness; emotional stability versus neuroticism and closedness versus openness to new experiences.

Empirical evidence exists to support the mediating role that social support and personality play in the stress-handling process in order to prevent burnout. Greenglass, Fiksenbaum and Burke (1996) found that social support by friends and family was associated with fewer burnout symptoms in teachers whilst Baruch-Feldman, Brondolo, Ben-Dayan and Swartz (2002) found that support from family members was associated with lower burnout amongst traffic officers. With regard to the relationship between personality and social support, Veselska et al. (2009) report a positive relationship between neuroticism and the dimensions of social support. With reference to personality, Alarcon, Eschleman and Bowling (2009), for example, found that emotional stability, extraversion, conscientiousness and agreeableness were negatively associated with emotional exhaustion. Similar conclusions were earlier made by Zellars, Perrewé and Hochwarter (2000) in a study using a sample of nurses.

In light of the literature review above and to achieve the research objectives, two hypotheses are formulated for this study, commencing with Hypothesis 1. 
Hypothesis 1: Personality combined with perceived social support predicts burnout: Scholars have investigated the association between burnout and personality. Kim, Shin and Umbreit (2007) found no relationship between extraversion and burnout or between agreeableness and burnout. However, neuroticism was found to be the most critical and influential burnout predictor. In a South African study (Storm \& Rothmann, 2003), the researchers found that low neuroticism, extraversion, openness to experience, agreeableness and conscientiousness were associated with lower emotional exhaustion, depersonalisation and higher personal accomplishment (Maslach et al. 2001). It further implies that neuroticism, low extraversion, low openness to experience, low agreeableness and low conscientiousness probably contribute to burnout. When correlating conscientiousness with engagement, Bakker, Demerouti and Ten Brummelhuis (2011) found that conscientiousness qualifies the main effects of positive affect on performance.

Social support provided by an individual's family, co-workers or other important people generates physical and emotional comfort in times of need (Galek et al. 2011). The aforementioned researchers further revealed that social support (supervisory support and family support) were negatively associated with burnout. In the same vein, Veselska et al. (2009) report a positive relationship between neuroticism and social support. It has been found that social support can buffer the negative effects of stress (Cheuk, Wong \& Rosen, 1994; Wong \& Cheuk, 2005). However during a study conducted by Kahn and Byosiere (1992) on social support, these researchers could not find positive effects of social support in their study. Jenkins and Elliott (2004) concluded that higher levels of support from co-workers were related to lower levels of emotional exhaustion amongst nurses. Furthermore, higher stressor scores were associated with higher levels of depersonalisation for staff reporting high levels of social support but not for those reporting low levels of support (a reverse buffering effect).

Hypothesis 2: Personality combined with perceived social support predicts vigour: Research that has conceptualised vigour in a work context is still rare (Sonnentag \& Niessen, 2008). In the same vein, literature explaining the effect of personality and social support on vigour is also hard to find. However, the literature on dispositional influences on affective states leads to the expectation that those scoring high on the personality trait of extraversion are more likely to experience vigour relative to those scoring high on neuroticism (Brief \& Weiss, 2002; Shirom, 2003). In addition, Goodwin, Cost and Adonu (2004) postulate that personality plays a role in seeking support from others. For example, extraverted people are more likely to actively seek out social support to cope with problems. Furthermore, Moos (2002) suggests that personality and social support simultaneously, and without isolation, have an effect on individual wellbeing. It can therefore be assumed that personality and social support have a similar influence on vigour as the latter is one dimension of well-being (Louw \& Viviers, 2010; Shirom, 2007).
Social support seems to play a similar role to the role that personality plays in the constitution of positive health outcomes such as vigour (Shirom, 2003). Extraverted individuals tend to seek social support. This contrasts with those scoring high on neuroticism, who rather avoid social contact (Schroevers, Ranchor \& Sanderman, 2003). Other research (Abu Sadat Nurullah, 2012; Cohen, 2004) has shown that interpersonal relationships can have both positive and negative influences on individual well-being and that supportive behaviour leads to better physical and mentalhealth outcomes (Cohen, Gottlieb \& Underwood, 2000; Taylor, 2011).

When considering the influence of personality and social support on the individual's well-being, it seems that the reason why some individuals suffer from burnout whilst others function vigorously under the same circumstances lies with the individual's adaptability to various threats or challenges with which he or she has to deal (O'Connel, McNeely \& Hall, 2008; Van Yperen \& Hagedoorn, 2003). Individual adaptability is reinforced by factors such as personality traits and social support during the coping process (Hobfoll \& Shirom, 2000; Moos, 1994; Shirom, 2003; Stephens, 2004). The coping process is explained by the buffering hypothesis, suggesting that personality traits and social support alleviate the harmful effects of environmental stressors on psychological well-being (Akert et al. 2007; Cassel, 1976; Cobb, 1976). Buffering also includes a cognitive component (e.g. appraisal) when experiencing a stressor (Cohen \& Mckay, 1984).

\section{Research design Research approach}

A non-experimental quantitative design with a crosssectional survey as the method to collect data was used in pursuit of the research objectives. According to Bryman and Bell (2011), cross-sectional designs suit investigations where the prevalence of a specific phenomenon is to be measured at one point in time (a snapshot) in a defined population (in this case, the police). Empirical data sets were used in the dataanalysis process.

\section{Research method \\ Participants and sampling}

The participants were employees of the South African Police Service (SAPS) from the provinces of the Eastern Cape and the Western Cape. They were employees who attended inservice training sessions at two provincial training centres, respectively. A convenient procedure with a non-probability sample $(N=505)$ was taken within a period of one week from officers who had completed at least a minimum of one year's service. The main ethnic groups (black, white, mixedrace and Indian) representing South African society were included in the sample. The sample is representative of both gender groups.

The sample produced frequencies and percentages of the relevant biographic characteristics of the sample. Males 
comprised the majority $(69.30 \%)$ of the participants. The majority (50.89\%) of participants were black people, followed by white $(34.46 \%)$, mixed-race $(12.48 \%)$ and Indian $(2.17 \%)$ people. In terms of the rank composition of the sample, the group captain or lieutenant-colonel $(33.86 \%)$ forms the majority of the sample, followed by the constables (28.72\%). Sergeants form the smallest group $(14.05 \%)$, followed by warrant-officers $(23.37 \%)$. The majority of participants have between 11 and 15 years of service $(27.70 \%)$, followed by those officers with between 16 and 21 years of service. The smallest group $(5.10 \%)$ has between 6 years and 10 years of service.

\section{Measuring instruments}

Shirom-Melamed Burnout Measure: The Shirom-Melamed burnout measure (SMBM) (Shirom, 2003) was used to measure burnout amongst participants. The SMBM is a 12-item, paper-and-pencil, self-report, seven-point frequency scale. The questionnaire taps an individual's experience of physical fatigue, emotional exhaustion and cognitive weariness with a typical item such as 'I feel tired' (Shirom, 2003). The SMBM measures the opposite affective state of vigour and is obliquely related to the latter construct (Schaufeli, Salanova, Gonzáles-Romá \& Bakker, 2002; Watson, Wiese, Vaidya \& Tellegen, 1999). The items in the questionnaire are set in a statement format. A value of 1 on the scale represents a response of 'Never or almost never', 2 represents 'very infrequently', 3 represents 'quite infrequently', 4 represents 'sometimes', 5 'quite frequently' 6 'very frequently', and 7 represents 'always or almost always'. Shirom, Niriel and Vinokur (2006) report a 3-factor structure for the SMBM with reliability indices varying between 0.93 and 0.91 .

Shirom-Melamed vigour measure: The Shirom-Melamed vigour measure (SMVM) (Shirom, 2004) was used to measure vigour amongst participants. Vigour is viewed as a core affect attributed to one's work milieu (Russel, 2003; Shirom, 2004). The SMVM is a 14-item, paper-and-pencil, self-report, seven-point intensity scale with a typical item such as 'I feel I have physical strength'. The items in the questionnaire are set out in a statement format. A value of 1 on the scale represents a response of 'Never or almost never', 2 represents 'very infrequently', 3 represents 'quite infrequently', 4 represents 'sometimes', 5 'quite frequently', 6 'very frequently', and 7 represents 'always or almost always' (Shirom, 2004). During the validation phase of the SMVM, an alpha of 0.94 was obtained with a sample of 2743 employees (Shirom, 2004). Armon, Shirom, Shapira and Melamed (2008) produced Cronbach alpha coefficients between 0.92 and 0.98. A principal component factor analysis with a varimax rotation confirmed three underlying factors, namely physical strength, emotional energy and cognitive liveliness. These three factors were also confirmed by other studies (Downey, Wefald \& Whitney, 2007; Shirom, Toker, Berliner, Shapira \& Melamed, 2008; Smith, Downey \& Whitney, 2006).

Multidimensional Scale of Perceived Social Support: The Multidimensional Scale of Perceived Social Support (MSPSS)
(Zimet et al., 1988) is a self-report instrument and was used to measure perceived social support. The MSPSS has 12 items with an intensity scale ranging from 1 ('very strongly disagree') to 7 ('very strongly agree'). The paper-and-pencil questionnaire is in a self-administered, statement format with a typical item such as 'I have a special person who is around when I am in need'. Zimet et al. (1988) report internal consistencies of $0.90,0.87$ and 0.85 , respectively, for the three subscales: significant other, family and friends. After conducting a confirmatory factor analysis (CFA), Basol (2008) confirmed the three-factor structure suggested by Zimet et al. with an excellent internal consistency of the full scale (Chronbach alpha 0.93).

Five Factor Inventory: The International Personality Item Pool (IPIP) Five Factor Inventory (FFI) (Goldberg, 1992) was used to measure personality in terms of the five factor model which provides a unifying personality framework that is useful in the prediction of job performance in some occupations (Barrick \& Mount, 1991; Costa \& McCrae, 2000; Robbins, 2003). For research purposes, the inventory is based on an abbreviated structure of personality, especially in the case of long protocols (Goldberg, 1992). The inventory is a self-report, paper-and-pencil instrument with five subscales. Each dimension includes a collection of bipolar rating scales. The instrument is a nine-point frequency scale on which individuals indicate whether they 'very' much agree, 'moderately' or 'do not' agree with an abbreviated statement that describes their personality traits on either side of each facet of a subscale. In total, the questionnaire consists of 25 abbreviated statements. A typical item is 'Silent versus Talkative'. The five broad dimensions (subscales) identified by Goldberg (1992) were: introversion versus extraversion (named extraversion); antagonism versus agreeableness (named agreeableness); lack of direction versus conscientiousness (named conscientiousness); emotional stability versus neuroticism (named neuroticism) and closedness versus openness to new experience (named openness to experience). The subscales of the Five Factor structure proposed by Goldberg (1992) were established through a process of three consecutive studies. Factor correlations are reported for each dimension. The correlation of introversion versus extraversion is 0.97 ; of antagonism versus agreeableness 0.93 ; of lack of direction versus conscientiousness 0.95 ; of emotional stability versus neuroticism 0.97 and of closedness versus openness to new experience 0.91. A model-fit exercise by Guenole and Chernychenko (2005) produced fit indices that represent excellent fit (i.e. global fit index $=0.97$, non-normed fit index $=0.94$ and comparative fit index $=0.96$ ) confirming the five-factor structure of the instrument.

\section{Research procedure}

The purpose of the study was explained to participants prior to commencement. Participants were gathered in a lecture room and voluntarily took part in the study whilst their identity remained anonymous. Instructions were given verbally, and no time limits were applied. Questionnaires 
were handed out to individuals in a booklet format. The researcher collected completed forms immediately after completion.

\section{Statistical analysis}

The responses were captured and statistically analysed utilising a statistical software package, namely Statistica (2008).

Descriptive statistics were used to analyse the distribution of scores. The frequency distribution of the items was checked in order to assess deviations from normality, and multivariate outliers were removed. It seems that the data is not normally distributed, and therefore Spearman's rank order correlation $(r s)$ was used to determine the relationships between the variables. The statistical significance was set at $p<0.05$. Effect sizes were used to assess the practical significance of the correlation coefficients (Steyn, 2005). Cohen (1988) gives the following guidelines for the social sciences: small effect size, $r=0.1-0.23$; medium, $r=0.24-0.36$; large, $r=0.37$ or larger. A cut-off point of 0.30 (medium effect) was set for the practical significance of correlation coefficients (Cohen, 1988; 1992).

Cronbach alpha coefficients $(\alpha)$ were used to assess the reliability of the measuring instruments. An exploratory factor analysis with varimax rotation was implemented to simplify factors during the confirmation of the factor structures of the measuring instruments in accordance with prior information provided by the developers. The researcher used the latent root criterion of eigenvalues greater than one to confirm the appropriate number of factors in each instrument (Hair, Black, Babin, Anderson \& Tatham, 2006).

A standard multiple-regression analysis was used to determine the size of the overall relationship between the predicted variables (dependent variables such as vigour and burnout) and the independent variables (such as perceived social support and personality). Furthermore, the regression analysis was also used to determine how much each independent variable uniquely contributed to the overall relationship as mentioned above. Separate analyses were conducted for each dependent variable. All predictor (independent) variables were entered into the regression equation at once (Aiken \& West, 1991). Regression analysis was interpreted in terms of explained variance.

\section{Results}

Descriptive statistics, Cronbach alpha coefficients and correlation coefficients (Spearman rank order correlations) for all the various sub-scales (dimensions) of the four instruments which were measured are illustrated in Table 1.

Table 1 shows the Cronbach alpha coefficients for the 14 sub-scales. The various Five Factor IPIP Inventory sub-scales produced coefficients that varied between 0.83 and 0.92 . The three sub-scales of the Multidimensional Scale of Perceived Social Support produced coefficients that vary between 0.81 and 0.86 . The Cronbach alpha coefficients produced by the Shirom-Melamed vigour measure vary between 0.88 and 0.91 followed by the Shirom-Melamed Burnout Measure which produced alphas that vary between 0.90 and 0.92 . According to Foxcroft and Roodt (2005), a Cronbach alpha coefficient of 0.65 or higher when making decisions about groups and 0.85 when making decisions concerning individuals is acceptable. The internal consistency of the instruments used in this research can therefore be regarded as acceptable.

The results displayed in Table 1 further show that the majority of the correlations are statistically significant $(p<0.05)$ with a few that are not statistically significant. Both statistical and practical-significant correlations are reported. A further inspection of Table 1 reveals that extraversion has a positive relationship with agreeableness (practically significant, large effect), conscientiousness (practically significant, medium effect) and openness to experience (practically significant, large effect), respectively $(r \mathrm{~s}[505]=0.42, p<0.05, r \mathrm{~s}=0.30$, $p<0.05, r \mathrm{~s}[505]=0.42, p<0.05)$. The same sub-scale's relationship with those of the MSPSS is also positive but with small effects, respectively. The same is observed amongst the

TABLE 1: Descriptive statistics, Chronbach alpha coefficients and correlation coefficients of the full and sub-scales used in the empirical study.

\begin{tabular}{|c|c|c|c|c|c|c|c|c|c|c|c|c|c|c|c|c|c|}
\hline Full scale & Sub- scale & $\mathbf{M}$ & SD & $\alpha$ & 1 & 2 & 3 & 4 & 5 & 6 & 7 & 8 & 9 & 10 & 11 & 12 & 13 \\
\hline FFI & Extra & 5.74 & 1.98 & 0.85 & - & - & - & - & - & - & - & - & - & - & - & - & - \\
\hline- & Agre & 7.20 & 1.71 & 0.87 & 0.42 & - & - & - & - & - & - & - & - & - & - & - & - \\
\hline- & Cons & 7.30 & 1.73 & 0.91 & 0.30 & 0.67 & - & - & - & - & - & - & - & - & - & - & - \\
\hline - & Open & 6.72 & 1.60 & 0.89 & 0.42 & 0.57 & 0.63 & - & - & - & - & - & - & - & - & - & - \\
\hline- & Neur & 4.53 & 2.15 & 0.87 & $-0.02 \dagger$ & $-0.07 \dagger$ & $-0.10 \dagger$ & $-0.01 \dagger$ & - & - & - & - & - & - & - & - & - \\
\hline MSPSS & Fam & 5.58 & 1.51 & 0.83 & 0.13 & 0.15 & 0.20 & 0.12 & 0.16 & - & - & - & - & - & - & - & - \\
\hline - & Frien & 4.66 & 1.74 & 0.86 & 0.16 & 0.17 & 0.13 & -0.01 & 0.16 & 0.41 & - & - & - & - & - & - & - \\
\hline - & Sig & 5.34 & 1.74 & 0.81 & 0.13 & 0.13 & 0.12 & -0.10 & 0.15 & 0.52 & 0.39 & - & - & - & - & - & - \\
\hline SMVM & Pstr & 4.21 & 1.58 & 0.88 & 0.20 & 0.18 & 0.20 & -0.20 & 0.23 & 0.22 & 0.17 & 0.22 & - & - & - & - & - \\
\hline- & men & 5.31 & 1.43 & 0.91 & 0.18 & 0.34 & 0.37 & -0.14 & 0.31 & 0.26 & 0.21 & 0.20 & 0.56 & - & - & - & - \\
\hline - & Cogl & 4.85 & 1.51 & 0.91 & 0.20 & 0.21 & 0.28 & -0.16 & 0.33 & 0.22 & 0.14 & 0.18 & 0.74 & 0.65 & - & - & - \\
\hline SMBM & Phys & 3.82 & 1.49 & 0.90 & $-0.04 \dagger$ & $-0.03 \dagger$ & $-0.03 \dagger$ & 0.25 & $-0.02 \dagger$ & -0.11 & $-0.03 \dagger$ & -0.09 & -0.37 & -0.89 & -0.26 & - & - \\
\hline - & Emex & 3.22 & 1.83 & 0.91 & $-0.07 \dagger$ & -0.12 & -0.15 & 0.28 & -0.12 & -0.20 & $-0.04 \dagger$ & -0.15 & -0.45 & -0.33 & -0.39 & 0.69 & - \\
\hline- & Cogw & 3.15 & 1.72 & 0.92 & -0.15 & -0.19 & -0.22 & 0.28 & -0.21 & -0.15 & $-0.05 \dagger$ & -0.09 & -0.39 & -0.33 & -0.38 & 0.57 & 0.73 \\
\hline
\end{tabular}

M, mean; SD, standard deviation; $\alpha$, alpha; FFI, Five Factor Inventory; MSPSS, multiple scale of perceived social support; SMVM, Shirom-Melamed vigour measure; SMBM, Shirom-Melamed burnout measure; EXTRA, extraversion; AGRE, agreeableness; CONS, consciousness; OPEN, openness; NEUR, neuroticism; FAM, family; FRIEN, friends; SIG, significant other; PSTR, police stress; burnout measure; EXTRA, extraversion; AGRE, agreeableness; CONS, consciousness; OPEN, openness; NEUR, neuroticism; FAM, family;
EMEN, emotional energy; COGL, cognitive liveliness; PHYS, physical fatigue; EMEX, emotional exhaustion; COGW, cognitive weariness.

$\dagger$, Not statistical significant; Statistical significance $p<0.05$ 
sub-scales of SMVM. For example, when physical strength is correlated with emotional energy and cognitive liveliness, practical-significant correlations (large effect) are produced $(r \mathrm{~s}[505]=0.56, p<0.05, r \mathrm{~s}[505]=0.74, p<0.05)$. What is of further significance to this research is that the sub-scales of the FFI reflect small to moderate effects with the sub-scales of the SMVM. As expected, the relationship of neuroticism with the SMVM is negative (practically significant, small effect) $(r \mathrm{~s}$ [505] $=-0.20, p<0.05, r \mathrm{~s}$ [505] $=-0.14, p<0.05, r \mathrm{~s}$ [505] $=-0.20, p<0.05)$. In contrast, neuroticism reflects a positive relationship with the SMBM (practically significant, medium effect) in terms of all three sub-scales $(r \mathrm{~s}[505]=0.25, p<0.05$, $r \mathrm{~s}[505]=0.28, p<0.05, r \mathrm{~s}[505]=0.28, p<0.05)$.

It is further observed that the sub-scales of the MSPSS correlate positively with the sub-scales of the SMVM. For example, family correlates with physical strength (practically significant, small effect), emotional energy (practically significant, medium effect) and cognitive liveliness (practically significant, small effect) $(r \mathrm{~s}[505]=0.22, p<0.05$, $\left.r_{s}[505]=0.26, p<0.05, r s[505]=0.22, p<0.05\right)$. However, the same sub-scale (family) has a negative relationship with the SMBM (practical significant, small effect) ( $r s$ [505] $=-0.11, p<$ $0.05, r s[505]=-0.15, p<0.05)$.

It is noticeable that the same sub-scales within constructs predominantly reflect large effects when correlated with each other. For example, extraversion reflects a (practically significant) large effect when it is correlated with the other sub-scales, respectively ( $r s$ [505] $=0.42, p<0.05, r s$ [505] $=$ $0.30, p<0.05, r s[505]=0.42, p<0.05)$. The same effects were noticed with regard to the sub-scales of the MSPSS, SMVM and SMBM. Such large effects indicate that the respective subscales measure the construct for the purpose for which it was developed. A last remark is that all correlations between the SMVM and the SMBM are negative (large effect), confirming that these instruments measure opposite constructs (Shirom, 2011).

Table 2 summarises the standard multiple regression analysis with dimensions of burnout (physical fatigue, emotional exhaustion and cognitive weariness) measured by the SMBM dimensions of personality (extraversion, agreeableness, conscientiousness, openness and neuroticism) measured by the FFI and dimensions of perceived social support (family, friends and significant other) measured by the MSPSS. Three separate, standard, multiple-regression analyses were conducted to determine the combined effect of personality and perceived social support on the burnout dimensions. With physical fatigue as the dependent variable, $\Delta R^{2}=0.07, F(11.49)=8.49, p<0.00$, the five personality traits and the three dimensions of perceived social support jointly explained seven per cent of the variance in physical fatigue. Only neuroticism $(\beta=0.12, t=5.90, p<0.00)$ and family support $(\beta=-0.08, t=-1.98, p<0.04)$ made unique and statistically significant contributions.

With emotional exhaustion as dependent variable, $\Delta R^{2}=$ $0.11, F(8.496)=8.92 p<0.00$, the five personality traits and the three dimensions of perceived social support jointly explained $11 \%$ of the variance in emotional exhaustion. Once again, only neuroticism $(\beta=0.22, t=5.64, p<0.00)$ and family support $(\beta=-0.24, t=-2.88, p<0.00)$ made unique and statistically significant contributions.

With cognitive weariness as dependent variable, $\Delta R^{2}=0.13, F$ $(8.49)=10.42, p<0.00$, the five personality traits and the three dimensions of perceived social support jointly explained $13 \%$ of the variance in cognitive weariness. Only neuroticism $(\beta=0.18, t=6.33, p<0.00)$ and family support $(\beta=-0.12$, $t=-1.97, p<0.04)$ made unique and statistically significant contributions. According to the abovementioned results, it is clear that neuroticism and family support are predictors of all three of the burnout dimensions. Hypothesis 1 is therefore partly accepted.

Three separate, standard, multiple-regression analyses were conducted to determine the combined effect of personality and perceived social support on the vigour dimensions. Table 3 summarises the standard, multiple-regression analysis with dimensions of vigour (physical strength, emotional energy and cognitive liveliness) measured by the SMVM, dimensions of personality (extraversion, agreeableness, conscientiousness, openness and neuroticism) measured by the FFI and dimensions of perceived social support (family, friends and significant other) measured by the MSPSS.

With physical strength as the dependent variable, $\Delta R^{2}=$ $0.12, F(8.49)=9.74, p<0.00$, the five personality traits and

TABLE 2: Multiple regression analysis with dimensions of personality and perceived social support as independent variables and physical fatigue, emotional exhaustion and cognitive weariness as dependent variables.

\begin{tabular}{|c|c|c|c|c|c|c|c|c|c|c|c|c|c|c|c|}
\hline \multirow{2}{*}{$\begin{array}{l}\text { Independent } \\
\text { variable }\end{array}$} & \multicolumn{5}{|c|}{ Physical fatigue } & \multicolumn{5}{|c|}{ Emotional exhaustion } & \multicolumn{5}{|c|}{ Cognitive weariness } \\
\hline & $B$ & SE & $\Delta R^{2}$ & $F$ & $\Delta R^{2}$ & $B$ & SE & $p$ & $F$ & $\Delta R^{2}$ & $B$ & SE & $p$ & $F$ & $\Delta R^{2}$ \\
\hline Sub-scales & - & - & - & 8.49 & 0.07 & - & - & - & 8.92 & 0.11 & - & - & - & 10.42 & 0.13 \\
\hline Extra & -0.02 & 0.02 & 0.29 & - & - & -0.00 & 0.04 & 0.85 & - & - & -0.05 & 0.03 & 0.10 & - & - \\
\hline Agree & -0.01 & 0.03 & 0.71 & - & - & -0.00 & 0.07 & 0.96 & - & - & -0.01 & 0.05 & 0.81 & - & - \\
\hline Concien & 0.03 & 0.04 & 0.44 & - & - & -0.09 & 0.07 & 0.18 & - & - & -0.06 & 0.05 & 0.21 & - & - \\
\hline Open & -0.00 & 0.03 & 0.96 & - & - & -0.01 & 0.06 & 0.85 & - & - & -0.07 & 0.05 & 0.13 & - & - \\
\hline Neur & 0.12 & 0.02 & $0.00 *$ & - & - & 0.22 & 0.03 & $0.00 *$ & - & - & 0.18 & 0.02 & $0.00 *$ & - & - \\
\hline Signif & -0.02 & 0.04 & 0.45 & - & - & -0.13 & 0.07 & 0.07 & - & - & -0.02 & 0.05 & 0.66 & - & - \\
\hline Family & -0.08 & 0.04 & $0.04^{*}$ & - & - & -0.24 & 0.08 & $0.00 *$ & - & - & -0.12 & 0.06 & $0.04 *$ & - & - \\
\hline Friend & 0.02 & 0.03 & 0.46 & - & - & 0.05 & 0.06 & 0.37 & - & - & 0.04 & 0.04 & 0.36 & - & - \\
\hline
\end{tabular}

$B$, beta; $\mathrm{SE}$, standard error; $F, F$-value; $\Delta R^{2}$, adjusted $R$-squared; EXTRA, extraversion; AGEE, agreeableness; CONSIEN, consciousness; OPEN, openness to new experience; NEUR, neuroticism; SIGNIF, significant other; FAMILY, family; FRIEND, friends

, Statistical significance $p<0.05$ 
TABLE 3: Multiple regression analysis with dimensions of personality and perceived social support as independent variables and physical strength, emotional energy and cognitive liveliness as dependent variables.

\begin{tabular}{|c|c|c|c|c|c|c|c|c|c|c|c|c|c|c|c|}
\hline \multirow{2}{*}{$\begin{array}{l}\text { Independent } \\
\text { Variable }\end{array}$} & \multicolumn{5}{|c|}{ Physical strength } & \multicolumn{5}{|c|}{ Emotional energy } & \multicolumn{5}{|c|}{ Cognitive liveliness } \\
\hline & $B$ & SE & $p$ & $F$ & $\Delta R^{2}$ & $B$ & SE & $p$ & $F$ & $\Delta R^{2}$ & $B$ & SE & $p$ & $F$ & $\Delta R^{2}$ \\
\hline Sub-scales & - & - & - & 9.74 & 0.12 & - & - & - & 12.78 & 0.15 & - & - & - & 11.52 & 0.14 \\
\hline Extra & 0.09 & 0.04 & 0.04 & - & - & -0.00 & 0.02 & 0.98 & - & - & 0.05 & 0.03 & 0.05 & - & - \\
\hline Agree & 0.00 & 0.06 & 0.96 & - & - & 0.07 & 0.04 & 0.07 & - & - & -0.06 & 0.04 & 0.14 & - & - \\
\hline Concien & 0.03 & 0.06 & 0.61 & - & - & 0.10 & 0.04 & $0.02^{*}$ & - & - & 0.06 & 0.04 & 0.15 & - & - \\
\hline Openess & 0.11 & 0.06 & 0.08 & - & - & 0.05 & 0.04 & 0.16 & - & - & 0.15 & 0.04 & $0.00^{*}$ & - & - \\
\hline Neur & -0.15 & 0.03 & $0.00^{*}$ & - & - & -0.05 & 0.02 & $0.02 *$ & - & - & -0.08 & 0.02 & $0.00 *$ & - & - \\
\hline Signif & 0.15 & 0.06 & $0.02 *$ & - & - & 0.07 & 0.04 & 0.09 & - & - & 0.07 & 0.04 & 0.08 & - & - \\
\hline Family & 0.14 & 0.07 & 0.06 & - & - & 0.09 & 0.05 & 0.06 & - & - & 0.10 & 0.05 & $0.04 *$ & - & - \\
\hline Friend & 0.05 & 0.06 & 0.36 & - & - & 0.08 & 0.04 & $0.03^{*}$ & - & - & 0.02 & 0.04 & 0.57 & - & - \\
\hline
\end{tabular}

$B$, beta; SE, standard error; $F, F$-value; $\Delta R^{2}$, adjusted $R$-squared; EXTRA, extraversion; AGREE, agreeableness; CONCIEN, consciousness; OPEN, openness to new experience; NEUR, neuroticism; SIGNIF, significant other; FAMILY, family; FRIEND, friends

*, Statistical significance $p<0.05$

the three dimensions of perceived social support jointly explained $12 \%$ of the variance in physical strength. Only neuroticism $(\beta=0.15, t=-4.21, p<0.00)$ and significant other $(\beta=-0.15, t=2.25, p<0.02)$ made unique and statistically significant contributions.

With emotional energy as dependent variable, $\Delta R^{2}=0.15$, $F(8.49)=12.78, p<0.00$, the five personality traits and the three dimensions of perceived social support jointly explained $15 \%$ of the variance in emotional energy. Again only conscientiousness $(\beta=0.10, t=2.26, p<0.02)$, neuroticism $(\beta=-0.05, t=-2.20, p<0.02)$ and friend support $(\beta=0.08$, $t=2.07, p<0.03)$ made unique and statistically significant contributions.

With cognitive liveliness as dependent variable, $\Delta R^{2}=0.14, F$ $(8.49)=11.52, p<0.00$, the five personality traits and the three dimensions of perceived social support jointly explained $14 \%$ of the variance in cognitive weariness. Only, neuroticism ( $\beta=-0.08, t=-3.44, p<0.00)$, openness to experience $(\beta=0.15, t=3.56, p<0.00)$ and family support $(\beta=0.10$, $t=2.02, p<0.04)$ made statistically significant contributions. Conscientiousness, openness to experience and all three of the perceived social support dimensions (significant other, friend support and family support) contributed to the prediction of vigour. Hypothesis 2 is therefore partly accepted.

\section{Discussion}

The main objective of the study was to investigate the combined effect of the big five personality traits and perceived social-support dimensions on burnout and vigour as two antipodes of affective experiences at work.

The first specific objective was to determine the combined effect of the five factor personality dimensions and the dimensions of perceived social support on the dimensions of burnout as defined in this article. The data analysis revealed that neuroticism is consistently related to all three burnout dimensions. This finding is supported by previous research (Bakker et al. 2006; Piedmont, 1993; Zellars et al. 2000). Extraversion is, however, also highlighted by the aforementioned researchers as a personality dimension that consistently relates to burnout, a finding that could not be supported by this research. In terms of previous research, consistency does not exist regarding agreeableness, openness to experience and conscientiousness (Morgan \& De Bruin, 2010).

Neuroticism reflects a significant positive correlation with physical fatigue, emotional exhaustion and cognitive weariness but an expected significant negative relationship with vigour (physical strength, emotional energy and cognitive liveliness) (Shirom, 2004; 2007). This trait also demonstrated a negative relationship with the three perceived social-support dimensions (friends, family and significant other), a finding that is analogous with research results produced by Onyishi, Obinna, Okongwu and Ugwu (2012). However, Veselska et al. (2009) report a positive relationship between neuroticism and the aforementioned three dimensions. According to McCrae and Costa (2006), the personality trait neuroticism is related to tendencies to experience negative affectivity and to expect the worst from situations. Such individuals also tend to underestimate selfperformance. In the same breath, Larsen and Buss (2005) suggest that police officers measuring high levels on this trait may tend to worry more about the outcome of events.

Extraversion was negatively related to cognitive weariness but produced no statistically significant relationships with physical fatigue and emotional exhaustion. This result is not consistent with a number of other research findings (Ganjeh, Arjenaki, Nori \& Oreyzi, 2009; Morgan \& De Bruin, 2010) in which extraversion was negatively related to emotional exhaustion. Extraversion showed a significant positive relationship with the vigour dimensions (physical strength, emotional energy and cognitive liveliness). This finding is consistent with results produced by Armon and Shirom (2011). Extraversion demonstrated a positive relationship with the three dimensions of the MSPSS. The latter finding is partly supported by results released by Onyishi et al. (2012) in which positive relationships were found between extraversion and two of the MSPSS dimensions (friends and family support). According to Zellars et al. (2000), extraversion refers to sociability and activity and to a predisposition to experience positive emotions (see also Shiota, Keltner \& John, 2006; Lucas \& Fujita, 2000). Therefore individuals who score high on this sub-scale tend to engage in social activities 
more readily. Friedlander, Reid, Shupak and Cribbie (2007) are further of the opinion that, in the case of university students, extraverted individuals may be more willing to seek assistance from others when experiencing difficulties with studies. Therefore, the same could possibly be expected from working individuals or individuals struggling with social issues.

Agreeableness produced a significant negative relationship with emotional exhaustion and cognitive weariness as well as a significant positive relationship with vigour's three dimensions. The relationship with perceived social support is also positive for all the MSPSS dimensions (friends, significant other and family support). Armon and Shirom (2011) confirm the positive relationship between agreeableness and emotional energy in a time study. Veselska et al. (2009) support the above relationship between agreeableness and the three dimensions of perceived social support. According to Ganjeh et al. (2009), individuals scoring high on agreeableness are less vulnerable to the effects of burnout. Such individuals may be more likely to receive social support and assistance with their problems (McCrae \& John, 1992; Thoreson, Kaplan, Barsky, Warren \& Chermont, 2003; Zellars et al. 2000). Individuals scoring low on agreeableness may not seek assistance with their problems due to their lack of trust in others (McCrae \& Costa, 2006).

Conscientiousness reflects a significant but weak negative relationship with emotional exhaustion and cognitive weariness. The weak negative relationship reflected by physical fatigue was not statistically significant. Armon, Shirom and Melamed (2012) confirmed negative relationships between conscientiousness, emotional exhaustion and cognitive weariness in a sample with healthy adults. With regard to vigour and perceived social support, conscientiousness demonstrated a positive relationship with the dimensions of all three of these constructs. Research by Armon and Shirom (2011) confirmed a similar relationship with vigour whilst results published by Veselska et al. (2009) are consistent with the positive relationship between conscientiousness and perceived social support produced in this research. Onyishi et al. (2012) could, however, not produce a significant relationship with significant others. According to McCrae and John (1992), individuals scoring high on conscientiousness are associated with a greater likelihood of obtaining work-related rewards. Goldberg (1990) is of the opinion that individuals scoring high on conscientiousness are more organised, plan ahead and are simultaneously thoughtful and thorough. Such individuals may be less overworked and tend to work consistently to meet deadlines before due dates (McCrae \& Costa, 2006; Zellars et al. 2000).

Openness to experience demonstrated a negative relationship with emotional exhaustion and cognitive weariness but no significant relationship with physical fatigue. With reference to burnout, Armon et al. (2012) reported similar results amongst inter-correlated variables. In this research, a positive relationship was reflected by the antithesis of burnout (vigour) and perceived social support in terms of all its dimensions. Veselska et al. (2009) reported similar results. Concerning vigour, Armon and Shirom (2011) found a positive relationship with cognitive liveliness. Openness to experience refers to the extent to which an individual is imaginative and curious and is receptive to variety (McCrae \& John, 1992). Past studies have found openness to experience to be closely linked to the vigour facet of cognitive liveliness such as intelligence, creativity and breadth of interest (Thoresen, Bradley, Bliese \& Thoresen, 2004) and, in general, with positive affective states (Armon \& Shirom, 2011; Steel, Schmidt \& Schultz, 2008). Individuals scoring high on this trait also tend to make use of more adaptive and flexible coping strategies (DeLongis \& Holtzman, 2005).

The results of the standard multiple regression analysis showed that neuroticism (as a personality trait) and family support (as a dimension of perceived social support) uniquely and consistently contribute to statistically significant variance in the burnout dimensions (e.g. physical fatigue, emotional exhaustion and cognitive weariness). Whilst the relationship between neuroticism and the burnout dimensions is positive, family support reflects a negative relationship with the latter dimensions. When considering the said relationships, one can assume that police officers scoring high on neuroticism are more prone to burnout (Storm \& Rothmann, 2003). Furthermore, it can also be assumed that individuals using family members as buffers during difficult times would experience less symptoms of burnout. Kokkinos (2007) found that neuroticism accounted for the most variance in emotional exhaustion, a finding that partially supports this study. Similarly, Hochwälder (2006) found that personality traits explained $7 \%$ of the variance in emotional exhaustion whilst Bakker et al. (2006) found that neuroticism was the sole predictor of emotional exhaustion and accounted for $13 \%$ of its variance. When considering the relationship with perceived social support, Hudek-Knežević, Krapić and Kardum (2006) found that support by significant others (co-workers) contributes $25 \%$ to the variance in emotional exhaustion, meaning that such support could reduce the effects of emotional exhaustion in potential burnout victims. It can be concluded that first specific objective was achieved.

The second specific objective of this research was to determine the combined effect of the five factor personality dimensions and perceived social support on the dimensions of vigour as defined in this article. The personality traits and perceived social supports', rather? contribution in variance are less consistent than in the case of burnout if one considers the standard multiple regression analysis in relation to the three dimensions of vigour. Conscientiousness contributes to the variance in emotional energy whilst neuroticism contributes to variance in all three of the vigour dimensions. The aforementioned are the only personality traits that contribute to the variance in vigour.

The above results have certain implications for police officers. Conscientious individuals would be thorough, careful and 
have the desire to do a task well whilst reflecting the capacity (energy) to execute it properly or to take part in a full day's work (McCrae \& Costa, 2006). Individuals reflecting physical strength would be more willing to consult with significant other people in the work context such as supervisors or colleagues, resulting in lower stress levels. This is because people experiencing physical strength have a high self-esteem and therefore find communicating with other people easier (Shirom, 2007). Individuals scoring high on neuroticism would probably experience low emotional energy whilst not having enough drive to execute a task normally or to think clearly (Shirom, 2003). Those scoring low on neuroticism can therefore be expected to experience the opposite. In addition, individuals scoring high on emotional energy may interact regularly with friends, being less prone to burnout (Shirom, 2003, 2007). Furthermore, individuals scoring high on cognitive liveliness have the ability to think clearly, a good memory and strong judgment. Such persons have a strong relationship with family members such as spouses or children, being less prone to burnout (Shirom, 2007).

A time study conducted by Armon and Shirom (2011) with an analysis via structural equation modelling (SEM) suggests that openness to experience accounts for variance in cognitive liveliness whilst agreeableness accounted for variance in emotional energy. The latter study does not support this research but rather suggests different personality traits to predict vigour. When looking at the multiple regression analysis with perceived social support as independent variable, significant other contributes to the variance in physical strength whilst family support contributes to the variance in cognitive liveliness. It can be assumed that interaction with other people may result in a healthy lifestyle as advice from other people may alleviate the negative effect of stressors or burnout (Zimet et al., 1988). Furthermore, interaction with other people may stimulate creative thinking. It is also clear that the combined effect of personality and social support predict vigour (Shirom, 2003). With reference to social support, Lord (2005) found contradicting results when his study revealed that, sometimes, social support can be stress inducing, and if prolonged, such individuals may develop burnout.

When considering previous research findings as cited above, personality traits such as extraversion, openness to experience, agreeableness, emotional stability and conscientiousness may be markers for selection purposes (Larsen \& Buss, 2005; Rothmann \& Coetzer, 2003). For example, high scores on conscientiousness and emotional stability are valid predictors for all occupations (Barrick \& Mount, 1991). High scores on extraversion and agreeableness will be predictors of management and sales positions (Barrick \& Mount, 1991; Gatewood et al., 2011). In the same vein, selection panels, especially those in the police services, may avoid individuals who score high on neuroticism as they tend to avoid social contact and are also not good examples of people with a vigorous and energetic lifestyle (Barrick \& Mount, 1991). However, individuals scoring high on neuroticism may be considered for positions in which sensitivity is required.
No previous studies could be found in which regression analyses were conducted with vigour (as defined by Shirom, 2007) as dependent variable and the five factor traits and perceived social support (as defined by Zimet et al., 1988). The second objective of this research was achieved.

\section{Recommendations for practitioners}

This study confirmed that neuroticism is positively related to all dimensions of burnout and consistently negatively related to dimensions of vigour. In the same breath, conscientiousness and openness to experience are positively related to the dimensions of vigour such as emotional energy and cognitive liveliness. One may argue that individuals scoring high on neuroticism should perhaps be excluded from highrisk positions or situations that are conducive to burnout. However Eastburg, Williamson, Gorsuch and Ridley (1994) present rather contrasting findings. They found that nurses who scored high on extraversion need more work-related peer support than introverted ones. Therefore, the exclusion of individuals scoring high on neuroticism from high-risk job positions must be viewed with caution until further research is done. Practical training in how to reduce burnout is a solution to the problem of fatigue. Several studies have shown that burnout can be reduced by means of effective training sessions focusing on the reduction of burnout (see Schaufeli \& Enzmann, 1998). Police management should consider the implementation of such programmes to enhance employee well-being.

In terms of social support, this study revealed that family support is consistently negatively related to all three burnout dimensions. Together with friend support, family support is positively related to emotional energy and cognitive liveliness respectively. According to the sample data, it seems that police officers rely heavily on family support. Police management must however take note that supervisor support is equally important and forms a buffer against prolonged stressors. Police officers do not operate in isolation (Louw \& Viviers, 2010), and social interaction in the office should be encouraged in operational designs.

\section{Limitations of the study}

The following limitations have been noted for this study. The study was a non-experimental design with a crosssectional survey as data-collection method, which limits the determination of cause-and-effect relationships. The opinions or feelings of participants are representative at one single point in time only. The sample is of a non-probability nature, which limits generalisation to the broader population.

\section{Suggestions for future research}

Future research projects should beemployed withlongitudinal designs to establish causal relationships amongst variables. More attention should also be given to vigour as the antithesis of burnout in research endeavours. The combined effect of personality traits and social support in the stress-mitigating process with vigour as dependent variable should also be 
explored further in different samples. Such an approach would be congruent with calls that researchers should study human strengths and positive psychological capacities in the social and work context (Peterson \& Seligman, 2004; Seligman, Steen, Park \& Peterson, 2005; Shirom, 2007).

\section{Conclusion}

This research sought to investigate the relationship between personality and perceived social-support dimensions and the dimensions of burnout and vigour. Although personality and social support were previously researched in similar research projects, the same instruments and the same definitions of constructs were not used. This research also had to deal with burnout and vigour as opposite affective work experiences in a police sample; something that has not been done before. A quantitative cross-sectional method was used to collect a data sample. Standard regression analyses revealed that neuroticism, a big five dimension, has a consistent relationship with all three of the burnout dimensions (physical fatigue, emotional exhaustion and cognitive weariness). In terms of perceived social support, family support reflects a similar relationship with all three burnout dimensions. These two dimensions (neuroticism and family support) therefore have a combined relationship with burnout. Neuroticism also reflects a negative relationship with all three vigour dimensions. Conscientiousness and openness to experience have a relationship with emotional energy and cognitive liveliness, respectively.

The three perceived social-support dimensions, namely significant other, family support and friend support, have a relationship with physical strength, cognitive energy and cognitive liveliness, respectively. From the above findings, it seems that individuals suffering from burnout have less mitigating resources like social support than those who execute their duties vigorously. In fact, it seems that there is a positive association between individuals using several forms of support and the energetic execution of their duties. This effect is therefore analogous with Hobfoll's (1998) conservation of resources theory. It can be concluded that this research adds to the body of knowledge on the role personality traits and social support play in the process of handling stress, specifically in the context of police work. In addition, significant information was generated in this research to emphasise the value of vigour, a construct that is currently under-researched.

\section{Acknowledgements Competing interests}

The author declares that he has no financial or personal relationship(s) that may have inappropriately influenced him in writing this article.

\section{References}

Abu Sadat Nurullah, M.A. (2012). Received and provided social support: A review of current evidence and future directions. American Journal of Health Studies, 27(3), 173-188. http://dx.doi.org/10.1177/0093854810374282
Adams, G.A., \& Buck, J. (2010). Social stressors and strain among police officers: It's not just the bad guys. Criminal Justice and Behavior, 37(9), 1030-1040.

Aiken, L.S., \& West, S.G. (1991). Multiple regression: Testing and interpreting interactions. Newbury Park, CA: Sage.

Akert, R.M., Aronson, E., \& Wilson, T.D. (2007). Social psychology. Upper Saddle River, NJ: Prentice Hall.

Alarcon, G., Eschleman, K.J., \& Bowling, N.A. (2009). Relationships between personality variables and burnout: A meta-analysis. Work \& Stress, 23(3), 244263. http://dx.doi.org/10.1080/02678370903282600

Anshel, M.H. (2000). A conceptual model and implications for coping with stressful events in police work. Criminal Justice and Behavior, 27, 375-400. http://dx.doi. org/10.1177/0093854800027003006

Antonovsky, A. (1987). Unravelling the mystery of health: How people manage stress and stay well. San Francisco, CA: Jossey-Bass.

Armon, G.D., \& Shirom, A. (2011). The across-time associations of the Five Factor model of personality with vigor and its facets using the bifactor model. Journa of Personality Assessment, 93(6), 618-627. http://dx.doi.org/10.1080/00223891 .2011 .608753

Armon, G., Shirom, A., Shapira, I., \& Melamed, S. (2008). On the nature of burnout-insomnia relationships: A prospective study of employed adults. Journal of Psychosomatic Research, 65(1), 5-12. http://dx.doi.org/10.1016/j. jpsychores.2008.01.012

Armon, G., Shirom, A., \& Melamed, S. (2012). The big five personality factors as predictors of changes across time in burnout and its facets. Journal of personality, 80(2), 403-427. http://dx.doi.org/10.1111/j.1467-6494.2011.00731.x

Bakker, A.B., Demerouti, E., \& Ten Brummelhuis, L.L. (2011). Work engagement, performance, and active learning: The role of conscientiousness. Journal of Vocational Behavior, 80, 555-564. http://dx.doi.org/10.1016/j.jvb.2011.08.008

Bakker, A.B., Demerouti, E., \& Verbeke, W. (2004). Using the job demands-resources model to predict burnout and performance. Human Resources Management 43(1), 83-104. http://dx.doi.org/10.1002/hrm.20004

Bakker, A.B, Schaufeli, W.B., Sixma, J., Bosveld, B., \& Van Dierendonck, D. (2000). Patient demands, lack of reciprocity, and burnout: A five-year longitudinal study among general practitioners. Journal of Organizational Behavior, 21(4), 425-441. http://dx.doi.org/10.1002/(SICI)1099-1379(200006)21:4\%3C425::AID JOB21\%3E3.0.CO;2-

Bakker, A.B., Van der Zee, K.I., Lewig, K.A., \& Dollard, M.F. (2006). The relationship between the big five personality factors and burnout: A study among voluntee counsellors. The Journal of Social Psychology, 13(5), 1-19.

Barrick, M.R., \& Mount, M.K. (1991). The big five personality dimensions and job performance: A meta-analysis. Personnel Psychology, 44(1), 1-26. http://dx.doi. org/10.1111/j.1744-6570.1991.tb00688.x

Baruch-Feldman, C., Brondolo, E., Ben-Dayan, D., \& Swartz, J. (2002). Sources of social support and burnout, job satisfaction, and productivity. Journal of Occupational Health Psychology, 7(1), 84-93.

Basol, G. (2008). Validity and reliability of the Multidimensional Scale of Perceived Social Support-Revised, with a Turkish sample. Social Behavior and Personality, 6(10), 1303-1314. http://dx.doi.org/10.2224/sbp.2008.36.10.1303

Brief, A.P., \& Weiss, H.M. (2002). Organizational behaviour: Affect in the workplace. Annual Review of Psychology, 53, 279-307. http://dx.doi.org/10.1146/annurev. psych.53.100901.135156

Bryman, A., \& Bell, E. (2011). Business research methods. (3rd edn.). New York, NY: Oxford University Press.

Cassel, J. (1976). The contribution of social environment to host resistance. American Journal of Epidemiology, 104(2), 107-123.

Cheuk, W.H, Wong, K.S., \& Rosen, S. (1994). The effects of spurning and social support on teacher burnout. Journal of Social Behaviour and Personality, 9(4), 657-664.

Cobb, S. (1976). Social support as a moderator of life stress. Psychosomatic Medicine, 38(5), 300-314. http://dx.doi.org/10.1097/00006842-197609000-00003

Coetzer, P., \& Emsley, R.A. (1996). Guidelines to the management of disability claims on psychiatric grounds. South African Medical Journal, 86(4), 1-8.

Cohen, J. (1988). Statistical power analysis for the behavioural sciences. (2nd edn.). Hillsdale, Ml: Lawrence Erlbaum and Associates.

Cohen, J. (1992). A power primer. Psychological Bulletin, 112(1), 155-159. http:// dx.doi.org/10.1037/00332909.112.1.155

Cohen, S. (2004). Social relationships and health. American Psychologist, 59(8), 676-684. http://dx.doi.org/10.1037/0003-066X.59.8.676

Cohen, S., Gottlieb, B., \& Underwood, L. (2000). Social relationships and health. In S. Cohen, L. Underwood \& B. Gottlieb (Eds.). Social support measurement and intervention: A guide for health and social scientists (pp. 3-25). New York, NY: intervention: A guide for
Oxford University Press.

Cohen, S., \& McKay, G. (1984). Social support, stress and the buffering hypothesis: A theoretical analysis. In A. Baum, S.E. Taylor \& J.E. Singer (Eds.). Handbook of psychology and health (pp. 253-267). Hillside, NJ: Erlbaum.

Cooper, C.I., \& Bagloni, A.J. Jnr. (1988). A structural model approach toward the development of a theory of the link between stress and mental health. British Journal of Medical Psychology, 61(1), 87-102. http://dx.doi. org/10.1111/j.2044-8341.1988.tb02767.x

Costa, P.T., \& McCrae, R.R. (2000). Stability and change in personality assessment: The revised NEO Personality Inventory in the year 2000. Journal of Personality Assessment, 68(1), 86-94. http://dx.doi.org/10.1207/s15327752jpa6801_7

DeLongis, A., \& Holtzman, S. (2005). Coping in context: The role of stress, social support, and personality in coping. Journal of personality, 73 (6), 1633-1656. $\mathrm{http}: / / \mathrm{dx}$.doi.org/10.1111/j.1467-6494.2005.00361.x 
Demerouti, E., Bakker, A.B., Nachreiner, F., \& Schaufeli, W.B. (2001). Job demands resources model of burnout. Journal of Applied Psychology, 86(3), 499-512. resources model of burnout. Journal of Applied

Dorz, S., Novara, C., Sica, C., \& Sanavio, E. (2005). Predicting burnout among HIV/AIDS and oncology health care workers. Psychology and Health, 18(5), 677-684. http:// dx.doi.org/10.1080/0887044031000141180

Downey, R.G., Wefald. A.J., \& Whitney, D. (2007, April). Does the Utrecht Work Engagement Scale (UWES) measure engagement? Paper presented at the Symposium on Engagement at the annual meeting of the society for Industrial and Organizational Psychology, New York, NY.

Eastburg, M.C., Williamson, M., Gorsuch, R., \& Ridley, C. (1994). Social support, personality and burnout in nurses. Journal of Applied Social Psychology, 24, 12331250. http://dx.doi.org/10.1111/j.1559-1816.1994.tb00556.x

Faber, B.A. (2000). Treatment strategies for different types of teacher burnout. Journal of Clinical Psychology, 56(5), 675-689. http://dx.doi.org/10.1002/(SICI)10974679(200005)56:5\%3C675::AID-JCLP8\%3E3.0.CO;2-D

Foxcroft, C.D. \& Roodt, G. (Eds.). (2005). An introduction to psychological assessment in the South African context. (3rd edn.). Cape Town: Oxford University Press.

Friedlander, L.J., Reid, G.J., Shupak, N., \& Cribbie, R. (2007). Social support, selfesteem, and stress as predictors of adjustment to university among first-yea undergraduates. Journal of College Student Development, 48(3), 259-275. http:// dx.doi.org/10.1353/csd.2007.0024

Galek, K., Flannelly, K.J., Greene, P.B., \& Kudler, T. (2011). Burnout, secondary traumatic stress and social support. Pastoral Psychology, 60, 633-649. http:// dx.doi.org/10.1007/s11089-011-0346-7

Ganjeh, S.J., Arjenaki, N.O., Nori, A., \& Oreyzi, H.R. (2009). The relationship of personality characteristics and burnout among nurses. Iranian Journal of Nursing and Midwifery Research, 14(4), 190-194.

Gatewood, R.D., Field, H.S., \& Barrick, M. (2011). Human resource selection. (7th edn.). Mason, $\mathrm{OH}$ : Cengage Learning.

Goldberg, L.R. (1990). An alternative 'description of personality': The big-five factor structure. Journal of Personality and Social Psychology, 59, 1216-1229. http:// dx.doi.org/10.1037/0022-3514.59.6.1216

Goldberg, L.R. (1992). The development of markers for the big-five factor structure. Psychological Assessment, 4, 26-42. http://dx.doi.org/10.1037/1040-3590.4.1.26

Goodwin, R., Cost, P, \& Adonu, J. (2004). Social support and its consequences: 'Positive' and 'deficiency' values and their implications for support and self-esteem. British Journal of Social Psychology, 43, 1-10. http://dx.doi. org/10.1348/0144666042038006

Greenglass, E., Fiksenbaum, L., \& Burke, R.J. (1996). Components of social support buffering effects and burnout: Implications for functioning. Anxiety, Stress \& Coping, 9(3), 185-197. http://dx.doi.org/10.1080/10615809608249401

Guenole, N., \& Chernychenko, O.S. (2005). The suitability of Goldberg's Big Five IPIP markers in New-Zealand: A dimensionality, bias, and criterion validity evaluation New Zealand Journal of Psychology, 34(2), 86-96.

Guse, T. (2010). Positive psychology and the training of psychologists: Students perspectives. SA Journal of Industrial Psychology, 36(2), Art. \#848, 6 pages. http:// dx.doi.org/10.4102/sajip.v36i2.848

Hair, J.F., Black, W.C., Babin, B.J., Anderson, R.E., \& Tatham, R.L. (2006). Multivariate data analysis. (6th edn.). Upper Saddle River, NJ: Pearson Prentice Hall.

Hakanen, J.J., Schaufeli, W.B., \& Ahola, K. (2008). The Job Demands-Resources model: A three-year cross-lagged study of burnout, depression, commitment, and work engagement. Work \& Stress, 22(3), 224-241. http://dx.doi. org/10.1080/02678370802379432

Hobfoll, S.E. (1998). The psychology and philosophy of stress, culture and community. New York, NY: Plenum. http://dx.doi.org/10.1007/978-1-4899-0115-6

Hobfoll, S.E., \& Freedy, J. (1993). Conservation of resources: A general theory applied to burnout. In W.B. Schaufeli, C. Maslach \& T. Marek (Eds.). Professional burnout: Recent developments in theory and research (pp. 115-135). New York, NY: Taylor \& Francis.

Hobfoll, S.E., \& Shirom, A. (2000). Conservation of resources theory: Applications to stress and management in the workplace. In R.T. Golembiewski (Ed.). Handbook of organization behaviour (2nd rev. edn.), (pp. 57-81). New York, NY: Marce Dekker.

Hochwälder, J. (2006). An empirical exploration of the effect of personality on general job-related mental ill health. Social Behavior and Personality, 34(1), 1051-1070. http://dx.doi.org/10.2224/sbp.2006.34.9.1051

Hudek-Knežević, J., Krapić, N., \& Kardum, I. (2006). Burnout in dispositional context: The role of personality traits, social support and coping styles. Review of Psychology, 13(2), 65-73.

Hugo, F.J., Emsley, R.A., Theron, F.H., De Villiers, N., \& Hemp, F. (2001). The prevalence of malingering in persons seeking compensation on the basis of neuropsychiatric symptoms. South African Journal of Psychiatry, 7(4), 110-114.

Jenkins, R., \& Elliott, P. (2004). Stressors, burnout and social support: Nurses in acute mental health settings. Journal of Advanced Nursing, 48(6), 622-631. http:// dx.doi.org/10.1111/j.1365-2648.2004.03240.x

Kahn, R.L., \& Byosiere, P. (1992). Stress in organization. In M.D. Dunnette \& L. Hough (Eds.). Handbook of industrial and organizational psychology (pp. 571-650). Palo Alto, CA: Consulting psychologists Press.

Kaplan, H.B. (1996). Psychosocial stress from the perspective of self theory. In H.B. Kaplan (Ed.), Psychosocial stress: Perspective on structure, theory, life-course, and methods (pp. 175-244). San Diego, CA: Academic Press.

Kim, H., Ji, J., \& Kao, D. (2011). Burnout and physical health among social workers: A three-year longitudinal study. Social Work, 56(3), 258-268. http://dx.doi. org/10.1093/sw/56.3.258
Kim, J.H., Shin, H.K., \& Umbreit, T.W. (2007). Hotel job burnout: The role of personality characteristics. Hospitality Management, 26(2), 421-434. http://dx.doi. org/10.1016/j.ijhm.2006.03.006

Kokkinos, C.M. (2007). Job stressors, personality and burnout in primary school teachers. British Journal of Educational Psychology, 77(1), 229-243. http://dx.doi. org/10.1348/000709905X90344

Kristensen, T.S, Borritz, M., Villadsen, E., \& Christensen, K.B. (2005). The Copenhagen Burnout Inventory: A new tool for the assessment of burnout. Work \& Stress: An International Journal of Work, Health \& Organizations, 19(3), 192-207.

Larsen, R.J., \& Buss, D.M. (2005). Differential personality psychology: Domains of knowledge about human nature. (2nd edn.). Ney York, NY: McGraw-Hill.

Lord, V.B. (2005). The stress change: The impact of changing a traditional police department to a community-orientated, problem-solving department. In $\mathrm{H}$. Copes \& M.L. Dantzker (Eds.). Policing and stress (pp. 503-522). Upper Saddle River, NJ: Pearson.

Louw, G.J. \& Viviers, A. (2010). An evaluation of a psychosocial stress and coping model in the police work context. SA Journal of Industrial Psychology, 36(1), Art. \#442, 11 pages. http://dx.doi.org/10.4102/sajip.v36i1.442

Lucas, R.E., \& Fujita, F. (2000). Factors influencing the relation between extraversion and pleasant affect. Journal of Personality and Social Psychology, 79(6), 10391056. http://dx.doi.org/10.1037/0022-3514.79.6.1039

Maslach, C. (1998). A multidimensional theory of burnout. In C.L. Cooper (Ed.) Theories of organizational stress (pp. 68-85). Oxford: Oxford University Press.

Maslach, C., Schaufeli, W.B., \& Leiter, M.P. (2001). Job Burnout. Annual Review of Psychology, 52, 397-422. http://dx.doi.org/10.1146/annurev.psych.52.1.397

McCrae, R.R., \& Costa, P.T. Jr. (2006). Personality in adulthood: A five factor theory perspective. (2nd edn.). New York, NY: Guilford Press.

McCrae, R.R, \& John, O.P. (1992). An introduction to the five-factor mode and its applications. Journal of Personality, 60(2), 175-215. http://dx.doi. org/10.1111/j.1467-6494.1992.tb00970.x

Mede, E. (2009). An analysis among personal variables, perceived self-efficacy and social support on burnout among Turkish EFL teachers. Inou University Journal of the Faculty of Education, 10(2), 39-92.

Mokoka, M.T., Rataemane, S.T., \& Dos Santos, M. (2012). Disability claims on psychiatric grounds in the South African context: A review. South African Journal of Psychiatry, 18(2), 34-41.

Moos, R.H. (1994, July). Conceptual and empirical advances in stress and coping theory. Paper presented at the 23rd International Congress of Applied Psychology, Madrid, Spain.

Moos, R.H. (2002). Context and coping: Toward a unifying conceptual framework. In D.F. Marks (Ed.). The healthy psychology reader (pp. 167-185). London: Sage Publications.

Morris, C.G., \& Maisto, A.A. (2012). Psychology: An introduction. (10th edn.). Upper Saddle River, NJ: Pearson/Prentice Hall.

Morgan, B., \& De Bruin, K. (2010). The relationship between the big five personality traits and burnout in South African university students. South African Journal of Psychology, 40(2), 182-191. http://dx.doi.org/10.1177/008124631004000208

Nakao, M. (2010). Work-related stress and psychosomatic medicine. Biopsychosocia Medicine, 4(4), 1-8. Retrieved June 27, 2013, from http://www.bpsmedicine. com/content/4/1/4

Newell, S. (2002). Creating the healthy organization, well-being, diversity and ethics. London: Thomson.

O'Connel, D.J., McNeely, E., \& Hall, D.T. (2008). Unpacking personal adaptability at work. Journal of Leadership \& Organizational Studies, 14(3), 248-259. http:// dx.doi.org/10.1177/1071791907311005

Okabayashi, H., Sugisawa, H., Takanashi, K., Nakatani, Y., Sugihara, Y., \& Hougham, G.W. (2008). A longitudinal study of coping and burnout among Japanese family caregivers of frail elders. Aging and Mental Health, 12(4), 434-443. http://dx.doi. org/10.1080/13607860802224318

Onyishi, I.E., Obinna, E., Okongwu, O.E., \& Ugwu, F.O. (2012). Personality and socia support as predictors of life satisfaction of Nigerian prisons officers. European Scientific Journal, 8(26), 111-125.

Peterson, C., \& Seligman, M.E.P. (2004). Character strengths and virtues: A handbook and classification. Washington DC: American Psychological Association.

Piedmont, R.L. (1993). A longitudinal analysis of burnout in the health care setting: The role of personal dispositions. Journal of Personality Assessment, 61(3), 457473. http://dx.doi.org/10.1207/s15327752jpa6103_3

Pienaar, J., Rothmann, S., \& Van de Vijver, F.J.R. (2007). Occupational stress, personality traits, coping strategies, and suicide ideation in the South African Police Service. Criminal Justice and Behavior, 34(2), 246-258. http://dx.doi. org $/ 10.1177 / 0093854806288708$

Pines, A., Aronson, E., \& Kafry D. (1981). Burnout: From tedium to personal growth New York, NY: The Free Press.

Reich, J.W., \& Zautra, A.J. (2002). Arousal and relationship between positive and negative affect: An analysis of the data of Ito, Cacioppo, and Lang (1998). Motivation and Emotion, 26, 209-222. http://dx.doi.org/10.1023/A:1021773013487

Robbins, S.P. (2003). Organizational behavior. (10th edn.). Upper Saddle River, NJ: Prentice Hall.

Rothmann, S., \& Coetzer, E.P. (2003). The big five personality dimensions and job performance. SA Journal of Industrial Psychology, 29(1), 68-74. http://dx.doi. org/10.4102/sajip.v29i1.88

Rothmann, S., \& Jorgensen, L.J. (2007). A model of work-related well-being for police members in the North West Province. Acta Criminologica, 2(4), 73-84. 
Russel, J.A. (2003). Core affect and the psychological construction of emotion Psychological Review, 110, 145-172. http://dx.doi.org/10.1037/0033295X.110.1.145

Ryan, R.M., \& Frederick, C. (1997). On energy, personality, and health: Subjective vitality as a dynamic reflection of well-being. Journal of Personality, 65, 529-565. http://dx.doi.org/10.1111/j.1467-6494.1997.tb00326.x

Salami, S.O. (2011). Job stress and burnout among lecturers: Personality and socia support as moderators. Asian Social Science, 7(5), 110-121. http://dx.doi. org/10.5539/ass.v7n5p110

Schaufeli, W.B., \& Bakker, A.B. (2004). Job demands, job resources, and their relationship with burnout and engagement: A multi-sample study. Journal of Organizational Behavior, 25, 293-315. http://dx.doi.org/10.1002/job.248

Schaufeli, W.B. \& Enzmann, D. (1998). The burnout companion to study and practice: A critical analysis. Philadelphia: Taylor \& Francis Ltd.

Schaufeli, W.B., Leiter, M.P., Maslach, C., \& Jackson, S.E. (1996). The Maslach Burnout Inventory-General Survey. In C. Maslach, S.E. Jackson \& M.P. Leiter (Eds.). Maslach Burnout Inventory. Palo Alto, CA: Consulting Psychologists Press. Schaufeli, W.B., Salanova, M., Gonzáles-Romá, V., \& Bakker, A. (2002). The measurement
of burnout and engagement: A confirmatory factor analytic approach. Journal of Happiness Studies, 3(1), 71-92. http://dx.doi.org/10.1023/A:1015630930326

Schroevers, M.J., Ranchor, A.V., \& Sanderman, R. (2003). The role of social support and self-esteem in the presence and course of depressive symptoms: A comparison
of cancer patients and individuals from the general population. Social Science \& Medicine, 57, 375-385. http://dx.doi.org/10.1016/S0277-9536(02)00366-0

Seligman. M.E.P., Steen, T.A., Park, N., \& Peterson, C. (2005). Positive psychology progress: Empirical validation of intervention. American Psychologist, 60(5), 410421. http://dx.doi.org/10.1037/0003-066X.60.5.410

Sheldon, K.M., Ryan, R.M., \& Reis, H. (1996). What makes for a good day? Competence and autonomy in the day and in the person. Personality and Social Psychology Bulletin, 22, 1270-1279. http://dx.doi.org/10.1177/01461672962212007

Shiota, M.N, Keltner, D., \& John, O.P. (2006). Positive emotion dispositions differentially associated with big five personality and attachment style. The Journal of Personality Psychology, 1(2), 61-71.

Shirom, A. (2003). The effects of work-related stress on health. In M.J. Schabracq J.A.M. Winnbust \& C.L. Cooper (Eds.). Handbook of work and health psychology. (2nd edn., pp. 63-83). New York, New York: Wiley.

Shirom, A. (2004). Feeling vigorous at work? The construct of vigor and the study of positive affect in organizations. In P.L. Perrewe \& D. Ganster (Eds.). Research in organizational stress and well-being: Emotional and physiological processes and positive intervention strategies (pp. 135-165, vol. 3). Oxford: Elsevier. http:// dx.doi.org/10.1016/S1479-3555(03)03004-X

Shirom, A. (2007). Explaining vigor: On the antecedents and consequences of vigor as a positive affect at work. In D.L. Nelson \& C.L. Cooper (Eds.). Positive organisational behaviour (pp. 86-100). London: Sage. http://dx doi. org/10.4135/9781446212752.n7

Shirom, A. (2009). Epilogue: Mapping future research on burnout and health. Stress and Health, 25(5), 375-380. http://dx.doi.org/10.1002/smi.1284

Shirom, A. (2011). Vigor as a positive affect at work: Conceptualizing vigor, its relations with related constructs, and its antecedents and consequences. Review of Genera Psychology, 5(1), 50-64. http://dx.doi.org/10.1037/a0021853

Shirom, A., \& Ezrachi, Y. (2003). On the discriminant validity of burnout, depression, and anxiety: A reexamination of the burnout measure. Anxiety, Stress and Coping, 16, 83-99. http://dx.doi.org/10.1080/1061580021000057059

Shirom, A., \& Melamed, S. (2006). A comparison of the construct validity of two burnout measures among two groups of professionals. International Journal of Stress Management, 13(2), 176-200. http://dx.doi.org/10.1037/1072of Stress Manar

Shirom, A., Niriel, N., \& Vinokur, A.D. (2006). Overload, autonomy, and burnout as predictors of physicians' quality of care. Journal of Occupational Health Psychology, 11(4), 328-342. http://dx.doi.org/10.1037/1076-8998.11.4.328

Shirom, A., Toker, S., Berliner, S., Shapira, I., \& Melamed, S. (2008). The effects of physical fitness and feeling vigorous on self-rated health. Health Psychology, 27(2), 567-575. http://dx.doi.org/10.1037/0278-6133.27.5.567
Sims, R.R. (2002). Managing organisational behavior. Westport, CT: Quorum Books.

Smith, M.R., Downey, R.G., \& Whitney, D. (2006, February). Two theories of engagement: Examining the scales Poster presented at the 27th Annual Industria/ Organizational Behavior Graduate Student Conference, Fairfax, Virginia, USA.

Söderfeldt, M., Söderfeldt, B., Ohlson, C-G., Theorell, T., \& Jones, I. (2000). The impact of sense of coherence and high-demand low-control job environment on self-reported health, burnout and psychophysiological stress indicators. Work \& stress, 14(1), 1-15. http://dx.doi.org/10.1080/026783700417195

Sonnentag, S. (2005). Burnout research: Adding an off-work and day-level perspective. Work \& Stress, 19(3), 271-275. http://dx.doi.org/10.1080/02678370500386473

Sonnentag, S., \& Niessen, C. (2008). Staying vigorous until work is over: The role of trait vigour, day-specific work experiences and recovery. Journal of Occupational and Organisational Psychology, 81, 435-458. http://dx.doi. org/10.1348/096317908X310256

Statistica. (2008). Statistical version 8. [Data analysis software system]. Tulsa: Statsoft Inc.

Steel, P., Schmidt, J., \& Schultz, J. (2008). Refining the relationship between personality and subjective well-being. Psychological Bulletin, 134(1), 138-161. http://dx.doi. org/10.1037/0033-2909.134.1.138

Stephens, C. (2004). Workplace strategies for prevention of PTSD. In H. Copes, \& M.L. Dantzker (Eds.). Policing and stress (pp. 140-157). Upper Saddle River, NJ: Pearson.

Steyn, H.S. (2005). Handleiding vir bepaling van effekgroottes-indekse en praktiese betekenisvolheid. Potchefstroom: Statistiese Konsultasiediens, Noordwes Universiteit.

Storm, K., \& Rothmann, S. (2003). The relationship between burnout, personality traits and coping strategies in a corporate pharmaceutical group. SA Journal of Industrial Psychology, 29(4), 35-42. http://dx.doi.org/10.4102/sajip.v29i4.128

Thoreson, C.J., Kaplan, S.A., Barsky, A.P., Warren, C.R., \& Chermont, D.K. (2003). The affective underpinnings of job perceptions and attitudes: A meta-analytic review and integration. Psychological Bulletin, 129(6), 914-945. http://dx.doi. review and integration. Psycholog
org/10.1037/0033-2909.129.6.914

Taylor, S.E. (2011). Social support: A review. In M.S. Friedman (Ed.). The handbook of health psychology (pp. 189-214). New York, NY: Oxford University Press.

Thoresen, C.J., Bradley, J.C., Bliese, P., \& Thoresen, J.D. (2004). The big five personality traits and individual job performance growth trajectories in maintenance and transitional job stages. Journal of Applied Psychology, 89(5), 835-853. http:// dx.doi.org/10.1037/0021-9010.89.5.835

Van Wijk, C.H., \& Waters, A.H. (2008). Positive psychology made special: A case study with naval specialists. Military Medicine, 173, 488-492.

Van Yperen, N.W., \& Hagedoorn, M. (2003). Do high job demands create intrinsic motivation, fatigue, or both?: The role of job control and job socia support. Academy of Management Journal, 46(3), 339-348. http://dx.doi. org/10.2307/30040627

Veselska, Z., Geckova, A.M., Gajolosova, B., Orosova, O., Van Dijk, J.P., \& Reijneveld, S.A. (2009). Socio-economic differences in self-esteem of adolescents influenced by personality, mental health, and social support. European Journal of Public Health, 20(6), 647-652. http://dx.doi.org/10.1093/eurpub/ckp210

Watson, W., Wiese, D., Vaidya, J., \& Tellegen, A. (1999). Two general activation systems of affect: Structural findings, evolutionary considerations, and psychobiological evidence. Journal of Personality and Social Psychology, 76, 820-838. http:// dx.doi.org/10.1037/0022-3514.76.5.820

Wong, K.S., \& Cheuk, W.H. (2005). Job-related stress and social support in kindergarten principals: The case of Macau. International Journal of Education Management, 19(3), 183-196. http://dx.doi.org/10.1108/09513540510590977

Zellars, K.L., Perrewé, P.L., \& Hochwater, W.A. (2000). Burnout in health care: The role of the five factors of personality. Journal of Applied Social Psychology, 30(8), 1570-1598. http://dx.doi.org/10.1111/j.1559-1816.2000.tb02456.x

Zimet, G.D., Dahlem, N.W., Zimet, S.G., \& Farley, G.K. (1988). The multidimensional scale of perceived social support. Journal of Personality Assessment, 52(1), 30-41. http://dx.doi.org/10.1207/s15327752jpa5201_2 